\title{
BURNOUT PREVENTION WITH PSYCHOEDUCATION IN TEACHERS
}

\author{
Mónika Veronika Szigeti \\ "Education and Society" Doctoral School of Education, University of Pécs (Hungary)
}

\begin{abstract}
Our research aims at prevention of burnout, which can be a protective factor in preventing career abandonment and can contribute to creating and maintaining a positive workplace climate. It also promotes the mental well-being and resilience of teachers and students. Therefore, burnout of teachers is especially important in Hungary, as the gradually increasing professional and administrative burden, the lack of social esteem, as well as the changed learning-teaching environment and the methodological shortcomings of general teacher training significantly increase the risk of burnout.

In our research, the staff of the Somogy County Educational Service Center has been involved, mainly special education teachers. The 116-person sample has been conducted with a version of the Maslach Burnout Inventory developed for educators. In our presentation, the test results are presented. According to our findings, out of the three subscales of the subjects' questionnaire, the highest scores were achieved in the Emotional Exhaustion subscale and the lowest in the Depersonalization subscale. However, the emotional exhaustion subscale did not indicate a high burnout value in the study population. The correlations of burnout risk with age and time spent as a teacher has been also analyzed.

Problem-focused and change-oriented psychological counseling models are attracting interest in the international literature today (Egan, 2010). By strengthening resilience and supporting a sense of growth, consultation techniques work to strengthen effective interpersonal communication and help the individual plan constructively for the future (Bonanno, 2004, 2005; Kelley, 2005; Linley \& Joseph, 2005; Litz, 2005; Maddi, 2005). All of this are relevant to our research because we plan to provide burnout prevention psychoeducation counseling programs to educators. The literature also mentions the phenomenon of learned helplessness, which has its roots in childhood and is a breeding ground for both depression and burnout (Seligman,1991). Learned inertia can influence members of the helping professions toward passivity (paralysis, loss of control, hopelessness, unresponsiveness) and is therefore particularly burdensome for the individual, along with the challenges of helping professions. Results of our research shed light on the burnout level of special educators, personality traits important for coping and related burnout prevention (e.g., empathy, psychological immune competence) and the applied coping mechanisms that guide burnout prevention psychoeducation as a comprehensive concept.
\end{abstract}

Keywords: Burnout syndrome, psychoeducation, consultation techniques, burnout prevention of teachers.

\section{Introduction}

"Psychoeducation is a professional information transfer method that aims to increase patients" knowledge about their illness and how to cope with it, and to emotionally process problems associated with the illness" (Bagdi, Harkai, Stoll, Ferenc, 2016, p.20). The focus of psychoeducation is on transfer of information and development of coping strategies. Its long-term goal is not to deal with complaints, but to maintain health and - if necessary - therapeutic cooperation, to develop skills and to change attitudes. To all this, the psychoeducation specialist provides information about symptoms of disease, treatment options, and various self-help techniques (Bagdi et al, 2016). It was Carol M. Anderson who began applying it in its current sense in the 1980s and developed a psychoeducational model for family treatment of schizophrenia (Anderson, 1983). A feature based on a synthesis of clinical experience and interdisciplinary research is that it provides information and guidance to help the family understand the symptoms of the disease, the patient's pathology needs, contribute to reducing family stress, and help the family eliminate isolation, by exploring the development potential of social network (Anderson, 1980). Psychoeducation of burnout syndrome should therefore be part of an institutional mental health strategy. Recognition of symptoms, knowledge of psychological, social characteristics of burnout can play an important role in prevention. Self-recognition allows for early therapeutic interventions, preventing more severe symptoms. 
The development of a method of structured and solution-oriented psychological counseling is attributed to Gerard Egan. The use of this method can be particularly useful for professionals at high risk of burnout. The consulting technique focuses on creating rapport, emotional support, helping identify and explore problems and resources, objective possibilities, and articulating realistic goals. An important element of the process is evaluation of results (Egan, 2011). Bonanno $(2004,2005)$ believes that resilient behavior is not as rare as initially thought and is facilitated by several factors. Toughness at the level of cognitive processes, such as personality traits and self-enhancement, as well as emotionally centered repressive coping, positive emotions and laughter contribute to resilient responses to stress. This also support the healthy functioning of personality for a long time. Linley and Joseph (2005) believe that to understand responses to traumatic life events, psychologist need to be familiar not only with process of resilience but also with psychopathology and adversarial growth. Maddi (2005) complements Bonanno's theory by emphasizing that toughness as a personality trait - as a pattern of action and attitude - provides an opportunity for a person to view stressors as a growth rather than a threatening factor.

Presented literature and performed study draw attention to the fact that phenomenon of burnout should also be addressed in the case of teachers of educational services centers. There is a need for continuous monitoring with repeated examinations and mental health assistance should be provided to teachers through psychoeducation, counseling procedures and supportive therapy to help them cope and become more resilient.

There are 19 counties in Hungary, which are the administrative units of the country. The population of the country on January 1., 2021 was 9.73 million (KSH, 2021). Somogy County is the fifth largest in Hungary. It has 248 settlements. It is one of the least populated counties in the country, with a 50 person/ $\mathrm{km} 2$ population density in 2021 , and the total population was 314.551 people on 1 st of January in 2020 (KSH, 2021). There are eight districts in the county, most of them have villages with hard-to reach settlements.

Figure 1. Map of Hungary, highlighting Somogy County (Retrievered: May 05, 2021, from http://www.szabadi.hu/elhelyezkedes).

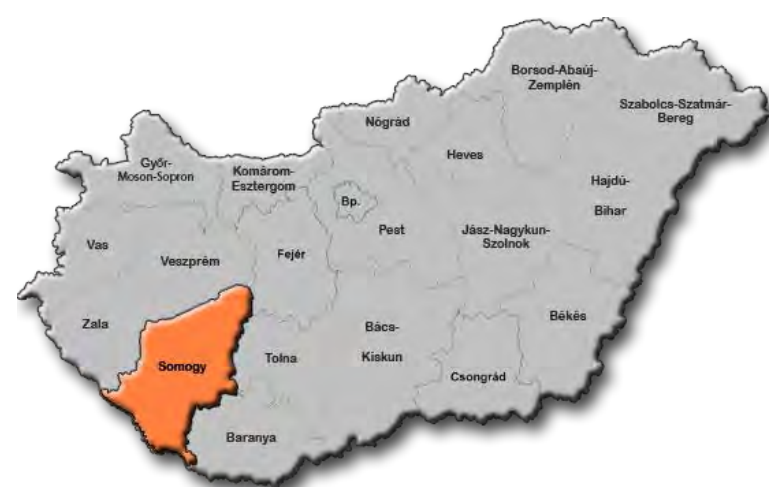

As the Head Director of Somogy County Educational Service Center, I am responsible for professional management of more than 250 colleagues. In addition, I have to monitor the educational and administrative tasks, which comes with a lot of responsibility. In the process, I can experience the high quality of my colleagues' work, which is often performed in less-than-ideal conditions.

The administrative burden is increasing, and we often treat families being in very difficult situation. Due the territorial peculiarities of the county, my colleagues spend a lot of time with traveling. We work with a high level of workload along with long waiting lists, which represents a significant stress potential for both employees and managers. These are also risk factors for burnout. The endangering workplace environmental factors are the following: the work environment does not suit individual needs, therefor the motivation of employees decreases; overburden, which leads to reduction intime, and resources spent on work; strict managerial control, winch prevents the employee from making autonomous decisions about her/his work, within the limits of her/his competence characteristic of the work (long working hours, administrative burdens, role conflicts, crises, poor communication, strict deadlines); lack of social support from colleagues and managers (lack of feedback and autonomy, low participation in decision); characteristics of the profession (continuous work with people, its impact on private life); hierarchy, operating rules (Galletta, Portoghese, Ciuffi, Sancassiani, D’Aloja, \& Campagna, 2016 and Borsi, n.d.).

The description on the definition of burnout syndrome comes from Herbert J. Freudenberger: "Burnout is a state of fatigue to produce the expected reward. It may be defined as the total depletion of physical and mental resources caused by excessive striving to reach an unrealistic work-related goal." (Freudenberger, 1975, p. 73.) 
ICD-11 does not define burnout as a disease. It classifies it as a category of "Factors Affecting Health Status or Contact with Health Services", and it is defined as a syndrome resulting from chronic work-related stress. Improper management of stress contributes to develop the syndrome. The three characteristics of it are the development of a feeling of exhaustion, emotional distance from work, and a decreased sense of professional efficiency. The phenomenon of burnout refers specifically to the occupational dimension, not to other areas of life (ICD-11, 2021).

\section{Goals}

In our research, it is aimed to get to know the burnout level of teachers by examining a group of employees of an institution who perform a special educational task, in the Somogy County Educational Service Center. To this end, the Maslach Burnout Inventory- Educator's Survey questionnaire has been used. Knowing the results of the study, we aimed to develop a mental hygiene program that helps educators' mental well-being, coping with stress, and contributes to resilient behavior. The mental health program includes psychoeducation of burnout syndrome, building on strengthening coping mechanism. In addition, the program provides opportunities for learning relaxation techniques and problem-focused, solution-oriented consultation.

\section{Methods}

\subsection{Presentation of the workplace of the teacher participating in the study: The Somogy County educational service center (Szigeti, 2019)}

The Somogy County Educational Service Center provides the professional service tasks specified in the Hungarian National Public Education Law (CXC. Law of 2011 on National Public Education) in 245 settlements. In addition, the headquarters institution, the organizational structure consists of eight district member institutions. The " $15 / 2013$. EMMI Decree on the Operation of Educational Service Centers" prescribes the tasks of the institution in the following fields: 1. special pedagogical counseling, early development and care, 2. expert examination, 3. educational counseling, 4. speech therapy, 5. continuing education career counseling, 6. conductive pedagogy, 7. physiotherapy, 8. school psychological and nursery school psychological service, 9. care for highly talented children and students. Various forms of care are provided on an outpatient basis and external workplaces, such as nurseries, public educational institutions, care homes for disabled and, if necessary, in families' homes. The qualification of the colleagues who work in the institution are wide. Special education teacher (speech therapist, teacher of mentally handicapped teacher for visually or hearing impaired), psychologist, physiotherapist, conductor, teacher, also a qualified professional. In addition to basic therapies, special development opportunities are also available in member-institutions.

\subsection{Participants in the study}

Employees of the Somogy County Educational Service Center - who works as a teacher participated in the study. At the time of research, in October 2019, there were 172 colleagues working in the institution as active teachers. 116 of them completed the questionnaire: the youngest was 22 years old and the oldest was 59 years old. There were 7 male and 109 female respondents.

\subsection{Presentation of the test procedure}

The examination took place in October 2019 in all member institutions and the headquarters of the Somogy County Educational Service Center. Sampling has been done by random selection. All completed questionnaires could have been included in the investigation. We recorded the data in a Microsoft Excel spreadsheet, and used these spreadsheets for the analysis.

As said the Maslach Burnout Inventory-Educators' Survey has been used for the study. We mastered it during my psychology studies in the University of Debrecen. The questionnaire consists of 22 items and explores the extent of teachers' burnout. The 22 questions can be answered on a seven-point scale, depending on the extent to which statement is specific to the respondent. The value 0 means you never feel the feelings expressed in the statement, and 6 means you feel it every day. By summing the response scores obtained for the items, the total burnout score is obtained. Items of the questionnaire can, in fact, be divided into three subscales:

- Emotional Exhaustion: nine items, feeling exhausted and emotionally overwhelmed in work

- Depersonalization: five items, impersonal reactions to students

- $\quad$ Personal Accomplishment: eight items, success and sense of competence at work (Mészáros, 2013).

\subsection{Research questions}

a. In which subscale teachers of the Somogy County Educational Service Center show the lowest and the highest values? 
b. Does the time spent on profession affect the appearance of burnout? Does the study result in higher values for new entrants (less than 5 years in teaching profession) and for those who have been working as a teacher for a longer time (minimum 35 years) than other people of the study population?

\section{Discussion}

The descriptive statistics of the collected data are representative for the employees of Somogy County Educational Service Center. The 116 random selected individual present $67,4 \%$ of the study population. In evaluating the questionnaire, individuals are classified into three categories: low (75 items), medium (37), and high (4) risk of burnout. To answer the first researcher's question, we have examined all three subscales of Maslach Burnout Inventory- Educators' Survey in the three categories above. Since the number of questions for each subscale are different in the questionnaire, we normalized the obtained scores, accordingly, thus obtaining a percentage with respect to the maximal possible score in each particular subscale. In case the individual has been classified as of low-level-burnout, we observed the lowest values on the Depersonalization subscale (with a maximum of $20 \%$ in that class) and the highest values on the Emotional Exhaustion subscale (maximum 60\%). For medium-level-burnout, we also obtained the lowest values on the Depersonalization subscale (maximum 50\%) and the highest ones on the Emotional Exhaustion subscale (between 50\% and 100\%). The values dominated in both subscales the respective values in the low-level-burnout category. Only four teachers in the sample have been classified as of high-level-burnout, no further conclusion on the subscales can be drawn for this group due to its small cardinality. The analysis of the impact of Personal Accomplishment in all categories yielded results ranging from $0-50 \%$. When analyzing the sample as a whole (that is, without differentiating between the low, medium, and high clusters), the respondents achieved the highest value as expected - on the Emotional Exhaustion subscale (40\%), the lowest value on the Depersonalization subscale (11\%). For the Personal Accomplishment the average was $27 \%$.

For the second researcher's question, the results indicate that the time spent on profession does not significantly affect the burnout-level, as can be seen in Figure 2.

Figure 2. Total score as a function of time spent on profession.

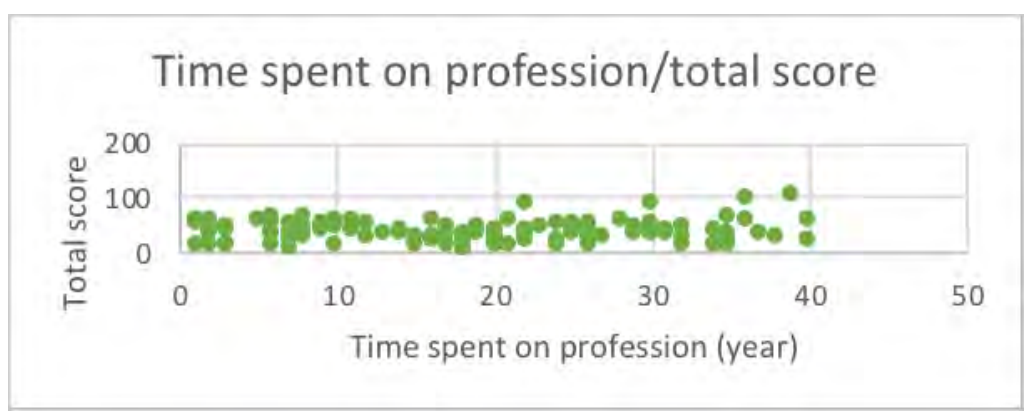

\section{Conclusions}

According to results of the study, teachers of Somogy County Educational Service Center cannot be characterized by a high level of burnout. The questionnaire indicated a high level of burnout in case of four teachers only, and a medium level in the case of 37 colleagues, so it is definitely worth addressing the issue. It is noteworthy, as expected, that we obtained the highest score on the Emotional Exhaustion subscale and the lowest on the Depersonalization subscale. The time spent as a teacher has not significantly affected the level of burnout. Given the results, as a secondary prevention of burnout, it is worth considering the use of institutional psychoeducation and solution-oriented psychological counseling as intervention techniques in the future.

\section{Acknowledgements}

Sponsored by the Cooperative Doctoral Program Doctoral Student Scholarship - KDP-2020. Application number 1010959. 


\section{References}

15/2013. EMMI Decree on the Operation of Educational Service Centers. in Hungarian: 15/2013. EMMI rendelet a pedagógiai szakszolgálati intézmények müködéséről. Retrieved May 23, 2021, from: https://net.jogtar.hu/j ogszabaly?docid=a1300015.emm (law)

Anderson, C. M. (1983). A Psychoeducational Model of Family Treatment in Schizophrenia. In Stierlin, H., Wynne, L.C., Wirsching, M. (Eds.): Psychosocial Intervention in Schizophrenia- An International View (227-235), Springer-Verlah Berlin Heidelberg GMBH. Retrieved May 07, 2021, from: https://link.springer.com/chapter/10.1007/978-3-642-68966-6 22

Anderson, C.M., Hogarty, G.E., Reiss, D. J. (1980). Family Treatment of Adult Schizophrenic Patient: A Psycho-educational Approach. Schizophrenia Bulletin, 6(3), 490-505. Retrieved May 07, 2021, from: https://doi.org/10.1093/schbul/6.3.490

Bagdi P., Harkai V., Stoll D.P., Ferenc M. (2016). Psychoeducation in spinal medicine. in Hungarian: Pszichoedukáció a gerincgyógyászatban. Retrieved May 07, 2021, from: https://www.researchgate.net/publication/319058846_PSZICHOEDUKACIO_A_GERINCGYOG YASZATBAN. 2021.05.07

Bonanno, G.A. (2004). Loss, Trauma, and Human Resilience: Have We Underestimated the Human Capacity to Thrive After Extremely Aversive Events? American Psychologist, 59(1), 8-20. Retrieved May 15, 2021, from: DOI:10.1037/0003-066X.59.1.20

Bonanno, G.A. (2005). Clarifying and Extending the Construct of Adult Resilience. American Psychologist, 60(3), 265-267. Retrieved May 07, 2021, from: DOI:10.1037/0003-066X.60.3.265b

Borsi A. (n.d.). The Phenomenon of Burnout in Teachers and Methodes of Supportive Intervention, in Hungarian: A kiégés jelensége pedagógusoknál és a segitö beavatkozás módszerei, Retrieved October 30, 2019, from: http://korhazlelkesz.hu/doc/Kieges.pdf

Central Statitics Office (2021). Hungary in Numbers, 2020. in Hungarian: Központi Statisztikai Hivatal (2021): Magyarország számokban, 2020. Retrieved May 20, 2021, from: https://www.ksh.hu/docs/hun/xftp/idoszaki/mosz/mosz20.pdf

CXC. Law of 2011 on National Public Education. in Hungarian: 2011. évi CXC. törvény a nemzeti köznevelésről. Retrieved: May 23, 2021, from: https://net.jogtar.hu/jogszabaly ?docid=a1100190.tv (law)

Egan, G. (2011). The Skilled Helper, in Hungarian: A képzett segitő. ELTE Eötvös Kiadó, Budapest.

Freudenberger, H. J. (1975). The staff burn-out syndrome in alternative institutions. Psychotherapy: Theory, Research \& Practice, 12(1), 73-82.

Galletta, M., Portoghese, I., Ciuffi, M., Sancassiani, F., D 'Aloja, E., Campagna, M. (2016). Working and Environmental Factors of Job Burnout: A Cross-sectional Study Among Nurses, Bentham Open, 12, 132-141. Retrieved May 06, 2021, from: https://benthamopen.com/FULLTEXT/CPEMH-12132

Kelley, T.M. (2004). Positive Psychology and Adolescent Mental Health: False Promise or True Breakthrow? Adolescence. 39(154), 257-278. Retrieved May 20, 2021, from: https://innateevolution.com/wp-content/uploads/2019/07/Positive-Psychology-and-AdolescentMental-Health-False-Promise-or-True-Breakthrough.pdf

Linley, P. A., \& Joseph, S. (2005). The Human Capacity for Growth Through Adversity. American Psychologist, 60(3), 262-264. Retrieved May 15, 2021, from: https://doi.org/10.1037/0003066X.60.3.262b

Litz, B. T. (2005). Has Resilience to Severe Trauma Been Underestimated? American Psychologist, 60(3), 262. Retrieved May 15, 2021, from: https://doi.org/10.1037/0003-066X.60.3.262a

Maddi, S. R. (2005). On Hardiness and Other Pathways to Resilience. American Psychologist, 60(3), 261-262. Retrieved May 15, 2021, from: https://doi.org/10.1037/0003-066X.60.3.261

Maslach, C., Jackson, S. E. (1981). Maslach Burnout Inventory Manual. Palo Alto, CA: Consulting Psychologists Press.

Mészáros V. (2013). Burnout in Healthcare - Correlates of Burnout and ways to prevention. In Hungarian: Kiégés az egészségügyben - A kiégés korrelátumai, valamint megelözésének lehetőségei, PhD Dissertation, Eötvös Lóránd University Faculty of Education and Psychology Budapest, Retrieved May 22, 2021, from: http://pszichologia.phd.elte.hu/vedesek/doktorjelolt_Meszaros-Veronika_disszertacio.pdf

Seligman, M.E. (1991). Learned Optimizmus: How to Change Mind and Your Life. New York. N.Y.: Pocket Books

Szigeti, M. (2019). Work Plan of Somogy County Educational Service Center, 2019/2020. School Year. In Hungarian: A Somogy Megyei Pedagógiai Szakszolgálat éves munkaterve, 2019/20. tanév, Kaposvár 